Medical Principles and Practice
Med Princ Pract 2017;26:542-546

DOI: $10.1159 / 000485036$
Received: January 31, 2017

Accepted: November 7, 2017

Published online: November 7, 2017

\title{
Human Washington University Polyomavirus in Patients with Respiratory Tract Infection in Kuwait
}

\author{
Sahar Sultan Essa Wassim Chehadeh Widad Al-Nakib \\ Department of Microbiology, Faculty of Medicine, Kuwait University, Safat, Kuwait
}

\section{Significance of Study}

- In this study performed in Kuwait, circulating genotypes of the Washington University (WU) polyomavirus found among hospitalized patients with viral respiratory tract infections (RTI) were type Ia and IIIb. Knowledge on the role of these circulating WU polyomavirus genotypes in RTI patients are still indefinable, and this article can contribute to the advancement in this field and be a starting point for future studies.

\section{Keywords}

Phylogenetic analysis - Respiratory tract infections ·

Washington University polyomavirus

\section{Abstract \\ Objective: To determine Washington University (WU) poly- omavirus strains circulating among hospitalized patients with respiratory tract infections (RTI) in Kuwait. Materials and Methods: Samples from 459 hospitalized children and adult RTI patients were screened for respiratory viruses by polymerase chain reaction from April 2013 to April 2016. The VP2 gene from WU virus (WUV)-positive samples was se- quenced and subjected to phylogenetic analysis. Results: Of the 459 hospitalized RTI patients, 18 (3.9\%) patients were positive for WUV infection. WUV infection was common among children aged $\leq 11$ years (9 patients, 50\%). Among the 18 WUV-infected hospitalized patients, viral co-infection was detected in 9 patients (50\%). The most common viruses associated with mixed infection were respiratory syncytial virus and human rhinovirus ( 2 patients, $11.1 \%$ each). Of the}

\section{KARGER}

E-Mail karger@karger.com www.karger.com/mpp

\section{The Author(s) \\ Published by S. Karger AG, Basel \\ Karger \\ Open access}

This is an Open Access article licensed under the Creative Commons Attribution-NonCommercial-4.0 International License (CC BY-NC) (http://www.karger.com/Services/OpenAccessLicense), applicable to the online version of the article only. Usage and distribution for commercial purposes requires written permission.
18 WUV-infected patients, 4 were sequenced and subjected to phylogenetic analysis. The circulating strains belong to type la and IIIb. Conclusion: This study enabled us to detect WUV among hospitalized RTI patients. Co-infection with other respiratory viruses was notable. Two circulating WUV genotypes (la and IIIb) were identified among hospitalized RTI patients in Kuwait.

(c) 2017 The Author(s)

Published by S. Karger AG, Basel

\section{Introduction}

Although viruses are the major cause of respiratory tract infections (RTI), the etiology of many suspected RTI cases remains unknown. However, since 2001, several human viruses have been identified from respiratory samples using various molecular methods [1-6], e.g., human metapneumovirus [1], human coronavirus [2], human bocavirus [3], and the human KI polyomaviruses and the human Washington University virus (WUV) [4-6]. 
These viruses were initially isolated from individuals with respiratory tract diseases, most of whom were children. Newly discovered viruses such as WUV [4-6] might be responsible for many respiratory tract illnesses whose cause has remained a mystery for decades.

The WUV is a novel member of the genus of polyomavirus in the polyomaviridae family. It is a double-strand deoxynucleic acid (DNA) virus with nonenveloped and icosahedral capsid [7]. Two human polyomavirus species called BK and JC viruses were first identified in 1971 from the urine sample of a kidney allograft recipient with chronic pyelonephritis and advanced renal failure [8] and from the brain sample of a patient with progressive multifocal leukoencephalopathy [9]. The KI virus was detected in nasopharyngeal aspirates and feces from RTI patients in Sweden [4]. Also, Gaynor et al. [5] described the detection and molecular characterization of WUV in patients with acute RTI.

Previously, the role of newly discovered viruses was studied in hospitalized patients with RTI using highly sensitive molecular techniques [10]. In this article, the phylogenetic analysis indicates that the circulating WUV genotypes among patients with viral RTI in Kuwait belong to Ia and IIIb.

\section{Materials and Methods}

Study Area and Study Population

A total of 459 hospitalized children and adult patients with RTI were screened for WUV during a 3-year period from April 2013 to April 2016 in respiratory samples collected from the Mubarak AlKabeer Hospital, Kuwait.

Nasopharyngeal aspirates were sampled from patients with RTI admitted to medical wards, intensive care unit (ICU), or pediatric ICU (PICU). Samples were delivered to the Virology Laboratory (Department of Microbiology, Faculty of Medicine, Kuwait University) within $2 \mathrm{~h}$ to decrease possible degradation of the viral nucleic acid. Ethical permission to perform this research study was granted by the Health Science Center and the KIMS (Kuwait Institute for Medical Specialization) Joint Committee on the Protection of Human Subjects in Research. Clinical data were obtained from the patients' medical records.

Amplification of the WUV VP2 Typing Region and

Phylogenetic Analysis

Molecular detection of respiratory viruses including WUV was performed as described earlier [10]. Genomic DNA was extracted from WUV-positive samples and stored at $-80^{\circ} \mathrm{C}$. Polymerase chain reaction (PCR) was carried out as follows: $3 \mu \mathrm{L}$ of the extracted DNA were mixed with $12.5 \mu \mathrm{L}$ of PCR mix that was composed of high-fidelity AmpliTaq Gold DNA Polymerase, $250 \mathrm{U}$ (0.625 U/ $\mu \mathrm{L})$, GeneAmp PCR Gold Buffer, $15 \mathrm{mM}$ Tris/HCl, pH 8.05, $50 \mathrm{mM} \mathrm{KCl}$, dNTP, $200 \mu \mathrm{M}$ each, $2.5 \mathrm{mM} \mathrm{MgCl}_{2}$ (Applied Biosystems, Foster City, CA, USA), and $0.4 \mu \mathrm{M}$ each of WUV
Table 1. Demographic and clinical features of patients infected with Washington University polyomavirus

\begin{tabular}{lc}
\hline & Patients, $n$ \\
\hline Sex & \\
$\quad$ Male & $9(50 \%)$ \\
$\quad$ Female & $9(50 \%)$ \\
Age & \\
$\quad \leq 11$ years & $9(50 \%)$ \\
$\quad 12-30$ years & $3(16.7 \%)$ \\
$>30$ years & $6(33.3 \%)$ \\
Median age, years & 13 \\
Hospital admission & \\
$\quad$ Medical ward & $12(66.7 \%)$ \\
Intensive care unit & $1(5.6 \%)$ \\
Pediatric intensive care unit & $5(27.8 \%)$ \\
Diagnosis & $7(38.9 \%)$ \\
$\quad$ Upper respiratory tract infection & $11(61.1 \%)$ \\
Lower respiratory tract infection & $10(55.6 \%)$ \\
Nationality & $8(44.4 \%)$ \\
$\quad$ Kuwaiti &
\end{tabular}

primers [11]. The primer sequences were as follows: WUT forward 5'-GGTACTCCCCATTATGCAGCC-3' and WUT-reverse $5^{\prime}$-GGTTGGAGGGGCTGCAA-3'. PCR amplification was carried out as described previously [12].

The samples were analyzed using sequencing analysis software (v 3.7; Applied Biosystems, Foster City, CA, USA). The WUV sequence alignment was performed with sequences that were present in the GenBank database (under accession Nos. EU711058, EU711057, EU711056, EU711055, EU711054, FJ890982, FJ890981, NC_009539, EU358769, EU358768, EU296475, EF444554, EF444553, EF444552, EF444551, and EF444550). The best available nucleotide substitution model was chosen using the FindModel application [13]. Epidemiological classification of WUV types was carried out as described before [11].

The evolutionary history was established using the neighborjoining method [14]. The percentage of replicate trees in which the associated taxa clustered together in the bootstrap test (1,000 replicates) were displayed next to the branches [15]. Bootstrap values $<50 \%$ were masked. The tree was made to scale, with branch lengths in similar units as those of the evolutionary distances used to complete the phylogenetic tree. The evolutionary distances were computed using the maximum composite likelihood method and were in the units of the number of base substitutions per site. Evolutionary analyses were conducted using Molecular Evolutionary Genetics Analysis version 5 (MEGA5) $[16,17]$.

\section{Statistical Analysis}

A descriptive statistical analysis using SPSS (version 20.0; SPSS, Chicago, IL, USA) was performed initially to identify the characteristics of the study population. Statistical analysis was done by $\chi^{2}$ test for categorical variables. Statistical significance was set at a value of $p \leq 0.05$. 


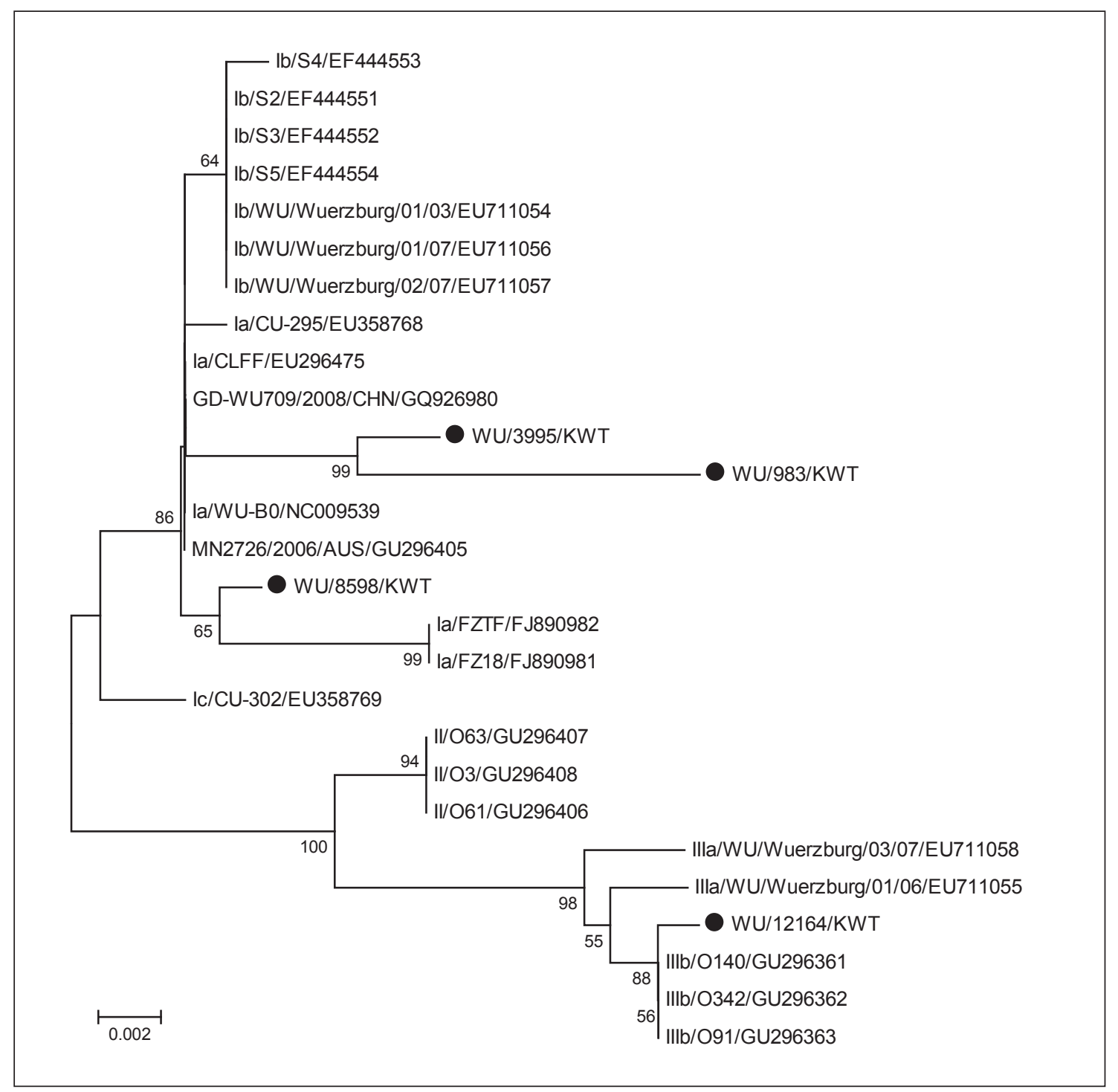

Fig. 1. Black circles represent Washington University polyomavirus (WUV) strains obtained in this study. A phylogenetic tree was constructed for each of the 3 WUV types using the sequence of the VP2 region of WUV isolates from Kuwait. The numbers next to the branch points of the tree are bootstrap values (1,000 replicates).

\section{Results}

Of the 459 hospitalized children and adult RTI patients (351 children and 108 adults), 18 (3.7\%) patients (9 males and 9 females) were diagnosed with WUV infection. Their age ranged from 1 month to 73 years. Of the 18 WUV-infected patients, 10 (56\%) were Kuwaiti, and 8 (44\%) were non-Kuwaiti (Table 1).

The 18 cases of WUV infection were distributed among various age groups; children aged $\leq 11$ years: 9 (50\%), 12 30 years: 3 (16.6\%), and $>30$ years: $6(33.3 \%)$. The median age of the patients infected was 13 years. No significant difference was observed regarding the age of patients infected with WUV $(p>0.05)$. Among the 18 patients infected with WUV, $12(66.7 \%)$ were admitted to medical wards and $6(33.3 \%)$ to ICU and PICU. No significant difference in prevalence was noted between WUV-infected patients admitted to medical wards and ICU and PICU $(p>0.05)$. Nine WUV-infected patients $(50 \%)$ were coinfected with both respiratory syncytial virus and human rhinovirus, followed by human bocavirus, human polyomavirus, $\mathrm{HCoV}-229 \mathrm{E}$ (2 patients, $11.1 \%$ each), and 1 pa- 


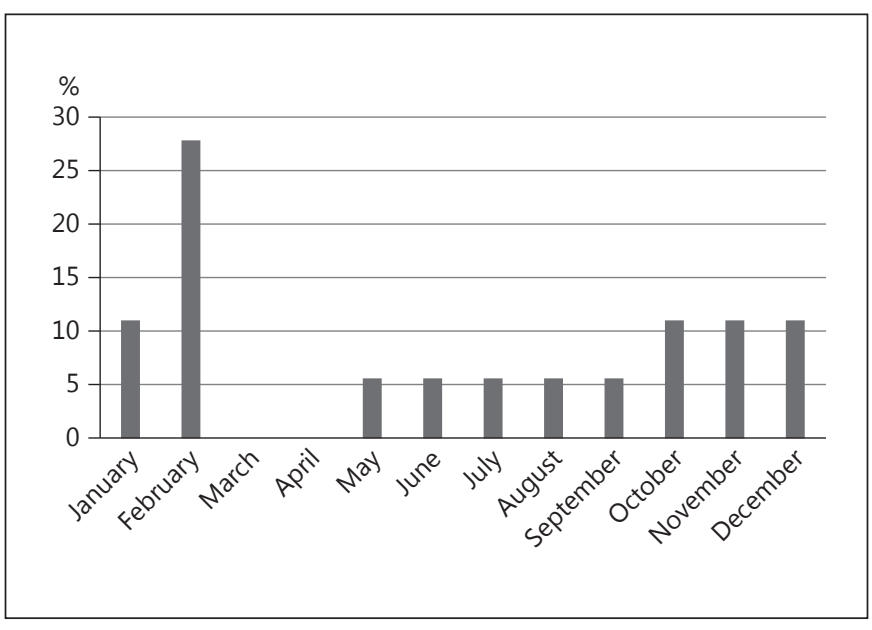

Fig. 2. Seasonal distribution of respiratory tract infections in hospitalized patients positive for Washington University virus from April 2013 to April 2016.

tient was co-infected with influenza virus A (5.6\%). Lower respiratory tract infections (LRTI) (pneumonia and bronchopneumonia) were detected in 11 hospitalized patients with WUV infection (61.1\%), and upper respiratory tract infection (URTI) (bronchitis) was detected in 7 patients (38.9\%). All 9 WUV-infected children (aged $\leq 11$ years) were diagnosed with LRTI. No significant difference in prevalence was noted between URTI and LRTI patients with WUV infection $(p>0.05)$. Also, the incidence of co-infection was statistically insignificant between LRTI and URTI patients $(p>0.05)$.

Four genomic WUV DNAs were sequenced from the 18 WUV-positive samples, and phylogenetic trees were constructed (Fig. 1). As can be seen from Figure 1, 3 of the circulating strains belong to type Ia and the 4th belongs to type IIIb. The circulating WUV strains among Kuwaitis belong to the type Ia and among non-Kuwaitis (Indians) to IIIb. The Indian patient is a resident of Kuwait for the past 10 years and did not leave Kuwait for the past 6 months, so the WUV strain IIIb is a circulating strain in Kuwait.

WUV was detected throughout the year except for March and April. The highest incidence (27.8\%) was detected during the month of February (Fig. 2).

\section{Discussion}

This study investigated the circulating WUV strains among hospitalized patients with viral RTI in Kuwait. WUV was identified in $3.9 \%$ of the hospitalized patients with RTI from 2013 to 2016, which is similar to previously reported data [10]. In other studies, the WUV detection rate reported in respiratory samples ranged from 2 to $34.9 \%[5,18-22]$. The data from this study support the worldwide distribution of WUV as a respiratory virus.

A high co-infection rate (50\%) was noted among WUV-infected patients in the current study. Notably, similar results were obtained by other studies with a coinfection rate extending from 47 to $83 \%[6,19,20-22]$. On the other hand, 9 hospitalized patients with a single WUV infection (50\%) were diagnosed with URTI or LRTI [19]. Although this study established the presence of the WUV as a single viral infection in $50 \%$ of the infected patients, the pathogenic potential of WUV in respiratory tract diseases remains unanswered due in part to high co-infection rates with other viruses and a deficiency in definite clinical correlations $[24,25]$. Co-infection would be an important area of further research to explore the underlying clinical patterns of mixed infections with other viruses.

From the 18 WUV-positive samples, only 4 genomic WUV DNAs were sequenced and phylogenetic trees constructed. This was probably due to the inconsistent collection of specimens or low viral load. Pneumonia and bronchopneumonia were more common (61\%) than URTI (39\%) among WUV-infected patients. Comparable results were reported among WUV-infected infants and young children from China [26].

Our data demonstrated that positive cases were detected throughout the year (except for March and April), with the highest peak in February (Fig. 2). In related studies, WUV infection has been identified in winter and early spring or summer $[5,27,28]$, while research from Thailand showed no seasonal distribution [29]. In China, the bulk of positive cases were detected in autumn and winter, with a sharp peak in November [26]. A more recent study from Shenzhen in China reported high peaks from March to May [30]. A full assessment of incidence, seasonality, and age distribution, mainly centered on epidemiological data, will be essential for medical decisionmaking, particularly decisions associated with the prescription of antiviral treatments, restriction of antibiotic therapy, and application of infection control policies.

\section{Conclusion}

The WUV was detectable among RTI patients, especially those diagnosed with bronchitis, pneumonia, and bronchopneumonia. Mixed viral infections with WUV 
were noticeable. Two genetic WUV lineages are circulating in Kuwait. To elucidate the role of WUV in RTI and to provide extensive knowledge on the genetic diversity of this virus, future investigations should be in case-control studies including larger patient cohorts.

\section{Acknowledgments}

We are thankful for the continuous support (research grant ZM 03/13) of the Research Sector, Kuwait University.

\section{References}

1 Williams JV, Harris PA, Tollefson SJ, et al: Human metapneumovirus and lower respiratory tract disease. N Engl J Med 2004;350: 443-450.

2 van der Hoek L, van der Hoek L, Pyrc K, et al: Identification of a new human coronavirus. Nat Med 2004;10:368-373.

3 Allander T, Tammi MT, Eriksson M, et al: Cloning of a human parvovirus. Proc Natl Acad Sci USA 2005;102:12891-12896.

4 Allander T, Andreasson K, Gupta S, et al: Identification of a third human polyomavirus. J Virol 2007;81:4130-4136.

5 Gaynor AM, Nissen MD, Whiley DM, et al: Identification of a novel polyomavirus from patients with acute respiratory tract infections. PLoS Pathog 2007;3:e64.

6 Bialasiewicz S, Whiley DM, Lambert SB, et al: Development and evaluation of real-time PCR assays for the detection of the newly identified $\mathrm{KI}$ and $\mathrm{WU}$ polyomaviruses. J Clin Virol 2007;40:9-14.

7 Cole $\mathrm{CN}$ : Polyomaviridae: the viruses and their replication; in Fields BN, Knipe DM, Howley PM (eds): Fundamental Virology, ed 3. Philadelphia, Lippincott, Williams \& Wilkins, 1996, pp 917-946.

8 Gardner SD, Field AM, Coleman DV, et al: New human papovavirus (B.K.) isolated from urine after renal transplantation. Lancet 1971; 1:1253-1257.

9 Padgett BL, Walker DL, Zurhein GM, et al: Cultivation of papova-like virus from human brain with progressive multifocal leucoencephalopathy. Lancet 1971;1:1257-1260.

10 Essa S, Owayed A, Altawalah H, et al: The prevalence of human bocavirus, human coronavirus-NL63, human metapneumovirus, human polyomavirus $\mathrm{KI}$ and WU in respiratory tract infections in Kuwait. Med Princ Pract 2015;24:382-387.
11 Bialasiewicz S, Rockett R, Whiley DW, et al: Whole-genome characterization and genotyping of global WU polyomavirus strains. J Virol 2010;84:6229-6234.

12 Al-Awadhi R, Chehadeh W, Al-Jassar W, et al: Phylogenetic analysis of partial L1 gene of 10 human papillomavirus types isolated most commonly from women with normal and abnormal cervical cytology in Kuwait. Arch Virol 2013;158:1687-1699.

13 http://www.hiv.lanl.gov/content/sequence/ findmodel/findmodel.html (accessed 11/5/ 2016).

14 Saitou N, Nei M: The neighbor-joining method: a new method for reconstructing phylogenetic trees. Mol Biol Evol 1987;4:406-425.

15 Felsenstein J: Confidence limits on phylogenies: an approach using the bootstrap. Evolution 1987;39:783-791.

16 Tamura K, Nei M, Kumar S: Prospects for inferring very large phylogenies by using the neighbor-joining method. Proc Natl Acad Sci USA 2004;101:11030-11035.

17 Tamura K, Peterson D, Peterson N, et al: MEGA5: Molecular Evolutionary Genetics Analysis using maximum likelihood, evolutionary distance, and maximum parsimony methods. Mol Biol Evol 2011;28:2731-2739.

18 Comar M, Zanotta N, Rossi T, et al: Secondary lymphoid tissue as an important site for WU polyomavirus infection in immunocompetent children. J Med Virol 2011;83:14461450 .

19 Zhuang WL, Lu XD, Lin GY, et al: WU polyomavirus infection among children in South China. J Med Virol 2011;83:1440-1445.

20 Le BM, Demertzis LM, Wu G, et al: Clinical and epidemiologic characterization of $\mathrm{WU}$ polyomavirus infection, St. Louis, Missouri. Emerg Infect Dis 2007;13:1936-1938.
21 Okada M, Hamada H, Sato-Maru H, et al: WU polyomavirus detected in respiratory tract specimens from young children in Japan. Pediatr Int 2013;55:536-537.

22 Essa S, Abdullah Owayed A, Altawalah H, et al: Mixed viral infections circulating in hospitalized patients with respiratory tract infections in Kuwait. Adv Virol 2015;2015:714062.

23 Abed Y, Wang D: WU polyomavirus in children, Canada. Emerg Infect Dis 2007;13: 1939-1941.

24 Babakir-Mina M, Ciccozzi M, Perno CF, et al: The novel KI, WU, MC polyomaviruses: possible human pathogens? New Microbiol 2011; $34: 1-8$.

25 Rao S, Garcea RL, Robinson CC, et al: WU and $\mathrm{KI}$ polyomavirus infections in pediatric hematology/oncology patients with acute respiratory tract illness. J Clin Virol 2011;52: 28-32.

26 Yuan X, JinY, Xie Z, et al: Prevalence of human $\mathrm{KI}$ and $\mathrm{WU}$ polyomaviruses in children with acute respiratory tract infection in China. J Clin Microbiol 2008;46:3522-3525.

27 Neske F, Blessing K, Ullrich F, et al: WU polyomavirus infection in children, Germany. Emerg Infect Dis 2008;14:680-681.

28 Bialasiewicz S, Whiley DM, Lambert SB, et al: Presence of the newly discovered human polyomaviruses KI and WU in Australian patients with acute respiratory tract infection. J Clin Virol 2008;41:63-68.

29 Payungporn S, Chieochansin T, Thongmee C, et al: Prevalence and molecular characterization of WU/KI polyomaviruses isolated from pediatric patients with respiratory disease in Thailand. Virus Res 2008;135:230-236.

30 Ying H, Guang-Yu L, Qiong W, et al: A 3-year prospective study of the epidemiology of acute respiratory viral infections in hospitalized children in Shenzhen, China. Influenza Other Respir Viruses 2014;8:443-451. 